\title{
RANCANG BANGUN MEDIA PEMBELAJARAN IPA (AYO MENGENAL HEWAN DAN TUMBUHAN) UNTUK KELAS 4 SD BERBASIS ANDROID
}

\author{
Yogiyana Aditama1); Devi Afriyantari Puspa Putri ${ }^{2)}$ \\ 1), 2) Program Studi Informatika, Universitas Muhammadiyah Surakarta \\ 1)yogiyanaaditama@gmail.com; ${ }^{2)}$ deviapputri2@gmail.com
}

\begin{abstract}
Natural science is one of the subject the related to daily life, that learned by student such grouping of animals, the life cycle of animals and plants. However in the learning process students are less motivated because the study method are less attractive. According to these problems natural science media using android platform was made for $4^{\text {th }}$ grade student because students still have a high interest in Android smartphones and animation. The purpose of the study is to produce interactive and interesting media for learning, so the students can learn natural science easily and pleasantly. Waterfall method used in designing process. The testing phase in this study uses black box testing method and user acceptance test with students and teachers as respondent. The overall result for testing and questionnaire has the average 93,4\%. It can be concluded that the application can run as expected and can be used as a media of learning for students.
\end{abstract}

Keywords : Android, Animal\&Plants, Animation, Learning Method, Natural Science.

\section{PENDAHULUAN}

Saat ini perkembangan teknologi mengalami kemajuan yang pesat [1], hal ini dibuktikan dengan banyaknya kemunculan software dan hardware baru yang belum pernah ada sebelumnya. Salah satu hal baru dalam sisi software adalah munculnya sistem operasi mobile baru bernama Android. Android merupakan sistem operasi yang digunakan pada ponsel pintar (smartphone). Saat ini penggunaan smartphone telah merambah seluruh tingkatan usia termasuk anak-anak, salah satu alasan anak-anak menggemari smartphone adalah adanya software berbasis animasi pada smartphone tersebut [2].

Program aplikasi berbasis multimedia untuk alat bantu pembelajaran ternyata mampu meningkatkan minat siswa yang dapat membantu pemahaman siswa apabila dibandingkan dengan hanya menggunakan buku teks saja [3].

Dalam proses pembelajaran IPA masih menggunkan cara konvensional yang cenderung kurang menarik dan membosankan sehingga siswa-siswi kurang maksimal dalam menerima pengetahuan yang mereka peroleh dari sekolah [4].

Maka berdasarkan masalah diatas penulis bermaksud untuk membuat sarana belajar yang menarik dan menyenangkan bagi siswa-siswi yaitu media pembelajaran IPA untuk kelas IV SD berbasis Android. Media pembelajaran berbasis animasi merupakan metode pembelajaran yang cukup perlu dipertimbangkan hal itu berdasarkan kebiasaan anak-anak yang lebih senang bermain daripada belajar dan masih memiliki ketertarikan yang tinggi terhadap game atau animasi.

\section{TINJAUAN PUSTAKA}

Penelitian terdahulu yang berjudul "Game Edukasi Pengenalan Cara Hidup Hewan Dan Tumbuhan Untuk Anak Usia Sekolah Dasar Kelas 4" oleh [5], menghasilkan sebuah game edukasi yang dapat membantu dan memotivasi siswa dalam memaksimalkan hasil belajarnya, dibuat dengan menggunakan software Macromedia Flash, dan penelitian yang berjudul "Game Edukasi Berbasis Android Sebagai Media Pembelajaran Untuk Anak Usia Dini” oleh [6] menghasilkan sebuah game pengenalan hewan dan mewarnai untuk anak usia dini, aplikasi ini dibuat dengan menggunakan software app inventor, pembuatan aplikasi ini bertujuan untuk memperkenalkan materi dengan lebih menarik dan menyenangkan.

Berdasarkan kedua penelitian tersebut terdapat kesamaan tujuan antara penulis dan peneliti terdahulu yaitu ingin menciptakan media pembelajaran yang menarik dan menyenangkan untuk anak serta dapat memotivasi minat belajar anak, namun dalam pembuatannya tentu saja terdapat beberapa perbedaan salah satunya adalah software yang digunakan penulis dalam pembuatan 
media pembelajaran ini adalah Construct 2 karena keunggulan Construct 2 adalah multiplatform sehingga dapat mempublikasikan hasil dari penelitian ini keberbagai platform hanya dengan satu project saja.

\section{METODE PENELITIAN}

Penulis menggunakan metode System Development Life Cycle (SDLC) atau biasa disebut dengan metode waterfall. Metode waterfall yang penulis gunakan adalah metode waterfall versi Sommerville karena metode ini merupakan metode yang terbaru dari metode waterfall yang telah dikembangkan sebelumnya. Gambaran tentang metode waterfall yang penulis gunakan tergambar pada diagram alir pada Gambar 1 .

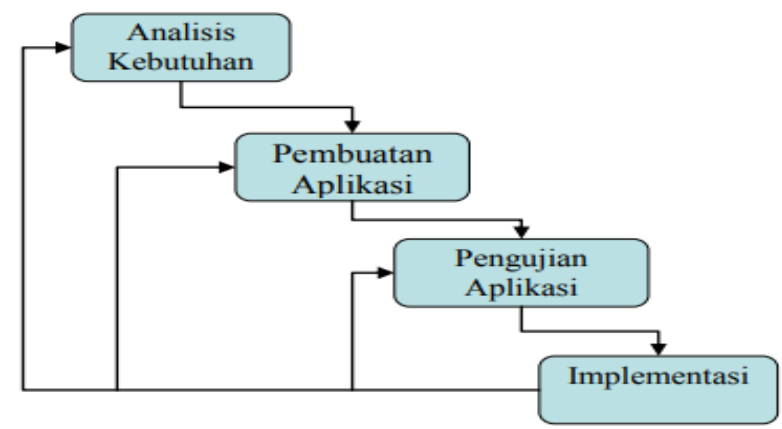

Gambar 1. Diagram Alir Penelitian

\subsection{Analisis Kebutuhan}

Tahap analisis kebutuhan ini dilakukan untuk mengetahui kebutuhan apa saja yang dibutuhkan untuk melakukan perancangan aplikasi yang bertujuan agar aplikasi dapat selesai tepat waktu dengan hasil yang baik. Beberapa kebutuhan dalam pembuatan aplikasi ini adalah kebutuhan hardware dan software, yang dijelaskan pada Tabel 1.

Tabel 1. Analisa Kebutuhan Hardware Dan Software

\begin{tabular}{|c|c|}
\hline Hardware & Software \\
\hline 1. Laptop & 1. Windows 8.1 Pro 64 \\
\hline processor & Bit \\
\hline Intel® Core I3, CPU & 2. Construct 2 v.r244 \\
\hline $\begin{array}{l}@ 2.70 \mathrm{GHz}, \quad \text { Ram } \\
\text { 4GB }\end{array}$ & $\begin{array}{l}\text { 3. Format } \\
\text { v. } 3.80\end{array}$ \\
\hline 2. Smartphone & 4. CorelDRAW X7 \\
\hline $\begin{array}{l}\text { Android } \text { Lenovo }^{\mathrm{TM}} \\
\text { A6010 }\end{array}$ & $\begin{array}{l}\text { 5. Google Chrome } \\
\text { 6. Website } \\
\text { www.phoneaap.com }\end{array}$ \\
\hline
\end{tabular}

\subsection{Pembuatan Aplikasi}

Tahapan pertama yang dilakukan sebelum perancangan aplikasi, dibuat diagram alir perancangan aplikasi agar dalam proses pembuatan aplikasi terfokus dan teratur, lalu dilakukan pengumpulan data dan materi yang akan diimplementasikan ke dalam game, data dan materi itu meliputi perancangan assets game baik itu gambar ataupun suara. Diagram alir perancangan aplikasi ditunjukkan pada Gambar 2.

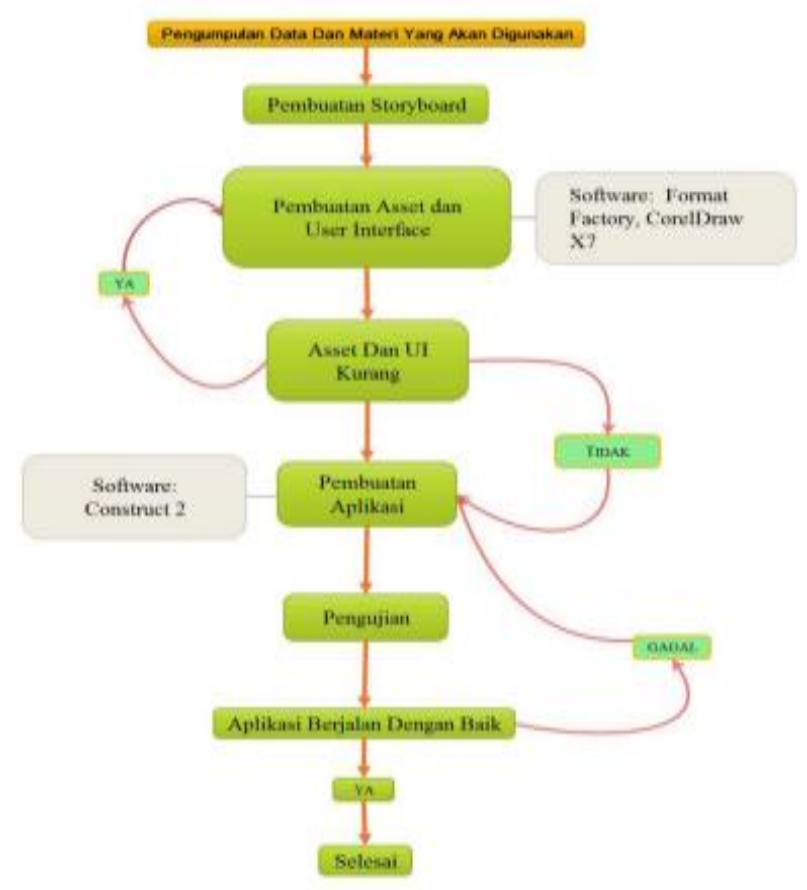

Gambar 2. Diagram Alir Perancangan Aplikasi

\subsection{Pengujian Aplikasi}

Pengujian aplikasi atau perangkat lunak adalah proses menjalankan atau memeriksa perangkat lunak dengan cara manual ataupun otomatis untuk mengetahui apakah software sudah memenuhi persyaratan atau perlu adanya perbaikan [7].

Pada pengujian aplikasi ini terdapat dua metode pengujian yaitu metode blacx box testing dan UAT ( User Acceptance Test) atau tingkat penerimaan pengguna. Metode black box testing menjadi metode yang cukup relevan mengingat nantinya tester software ini merupakan individu yang masih awam tentang software dan teknologi informasi, sedangkan user acceptance test adalah proses pengujian oleh user dan menghasilkan dokumen untuk dijadikan bukti bahwa aplikasi yang telah dikembangkan sudah dapat diterima oleh user dan hasil pengujiannya dianggap memenuhi kebutuhan pengguna [8], oleh karena itu dibuatlah kuisioner dengan menggunakan 
skala likert 5 skala yaitu STS (Sangat Tidak Setuju), TS (Tidak Setuju), N (Neutral), S (Setuju), SS (Sangat Setuju) untuk memudahkan pengumpulan data. Adapun kuisioner tersebut ditunjukkan pada Tabel 2.

Tabel 2. Kuisioner Pengujian Aplikasi

\begin{tabular}{|c|c|c|c|c|c|c|}
\hline \multirow[t]{2}{*}{ No. } & \multirow[t]{2}{*}{ Pertanyaan } & \multicolumn{5}{|c|}{ Pilihan Jawaban } \\
\hline & & SS & $\mathrm{S}$ & $\mathrm{N}$ & TS & STS \\
\hline 1. & $\begin{array}{l}\text { Apakah } \\
\text { aplikasi ini } \\
\text { menarik? }\end{array}$ & & & & & \\
\hline 2. & $\begin{array}{l}\text { Apakah } \\
\text { aplikasi ini } \\
\text { mudah } \\
\text { digunakan? }\end{array}$ & & & & & \\
\hline 3. & $\begin{array}{l}\text { Apakah } \\
\text { tombol- } \\
\text { tombolnya } \\
\text { mudah } \\
\text { dimengerti dan } \\
\text { mudah } \\
\text { digunakan? }\end{array}$ & & & & & \\
\hline 4. & $\begin{array}{l}\text { Apakah } \\
\text { bahasa yang } \\
\text { digunakan } \\
\text { mudah } \\
\text { dimengerti? }\end{array}$ & & & & & \\
\hline 5. & $\begin{array}{l}\text { Materi } \\
\text { pembelajaran } \\
\text { mudah } \\
\text { dipahami }\end{array}$ & & & & & \\
\hline 6. & $\begin{array}{l}\text { Tampilan } \\
\text { aplikasi tidak } \\
\text { membosankan }\end{array}$ & & & & & \\
\hline 7. & $\begin{array}{l}\text { Pertanyaan } \\
\text { kuis mudah } \\
\text { dijawab }\end{array}$ & & & & & \\
\hline 8. & $\begin{array}{l}\text { Aplikasi ini } \\
\text { membantu } \\
\text { belajar materi } \\
\text { pembelajaran } \\
\text { mengenal } \\
\text { hewan dan } \\
\text { tumbuhan } \\
\text { disekitar kita }\end{array}$ & & & & & \\
\hline 9. & $\begin{array}{l}\text { Aplikasi ini } \\
\text { mampu } \\
\text { meningkatkan } \\
\text { minat belajar } \\
\text { IPA }\end{array}$ & & & & & \\
\hline 10. & $\begin{array}{l}\text { Tombol-tombol } \\
\text { berfungsi } \\
\text { dengan baik }\end{array}$ & & & & & \\
\hline
\end{tabular}

\subsection{Implementasi}

Setelah tahap-tahap sebelumnya selesai maka tahap implementasi adalah tahapan terakhir pada metode yang digunakan penulis, pada tahap ini software akan diperkenalkan dan memberi pelatihan tentang pengoperasian aplikasi ini kepada siswa-siswi kelas 4 SD Negeri 1 Repaking beserta guru, agar nantinya aplikasi dapat dimanfaatkan dengan sebagaimana mestinya.

\section{HASIL DAN PEMBAHASAN}

Setelah tahapan sebelumnya telah selesai dilakukan maka pada penelitian ini menghasilkan sebuah aplikasi media pembelajaran (Ayo Mengenal Hewan Dan Tumbuhan Di Sekitar Kita). Adapun hasil dari pembuatan aplikasi ini dijelaskan sebagai berikut :

\subsection{Tampilan Aplikasi}

\subsubsection{Halaman Awal}

Tampilan awal aplikasi ditunjukkan pada Gambar 3.

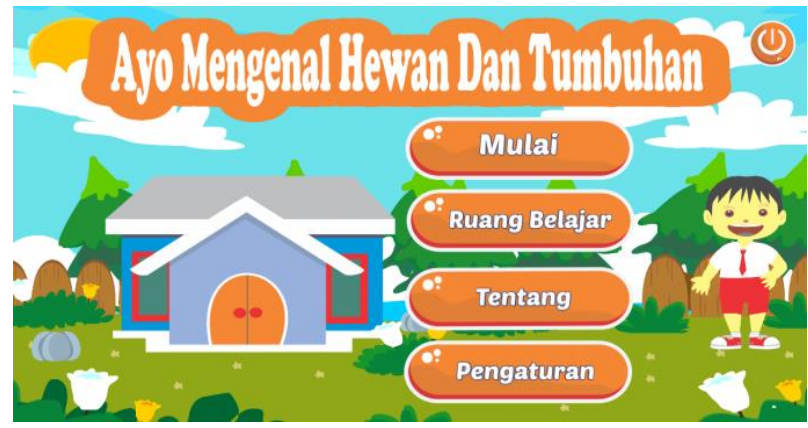

Gambar 3. Halaman Awal Aplikasi

Pada halaman awal ini terdapat beberapa menu pendukung aplikasi yaitu menu tentang dan menu pengaturan yang tampilannya ditunjukkan pada Gambar 4 dan Gambar 5.

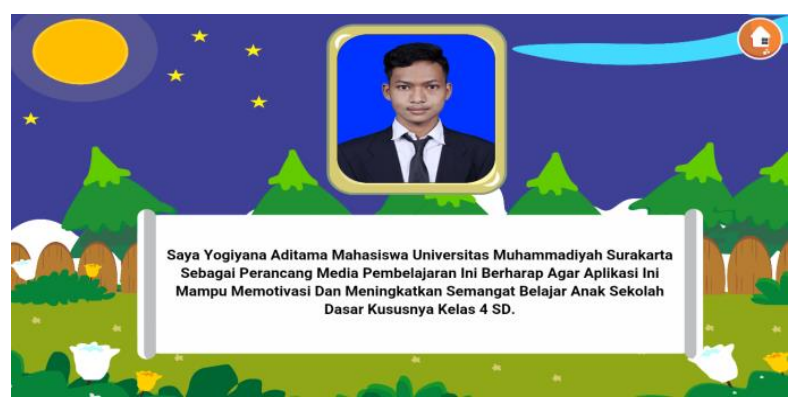

Gambar 4. Halaman Tentang

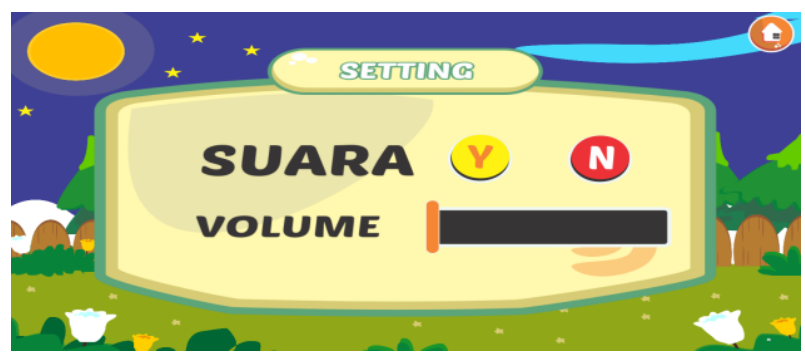

Gambar 5. Halaman Pengaturan 


\subsubsection{Menu Mulai}

Pada halaman mulai ketika user mengklik tombol mulai maka ditampilkan halaman kuis yang berisi 35 soal dari materi ruang belajar, apabila user salah memilih jawaban atau waktu habis maka user akan dialihkan ke halaman game over. Adapun tampilannya ditunjukkan pada Gambar 6 dan Gambar 7.

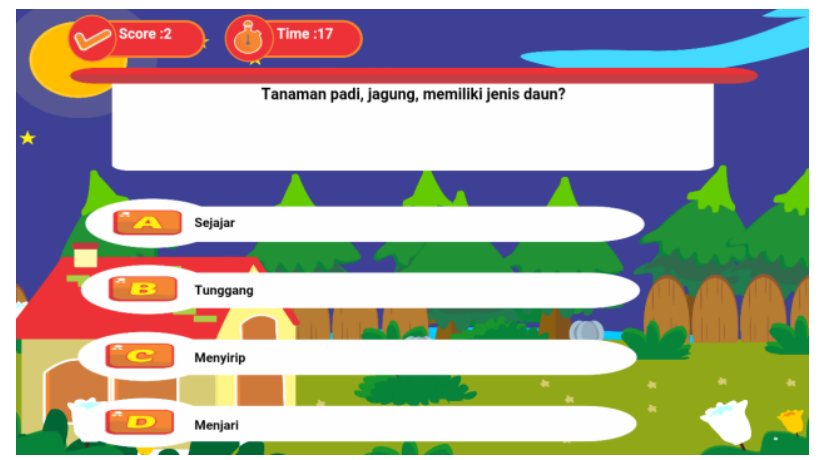

Gambar 6. Halaman Kuis

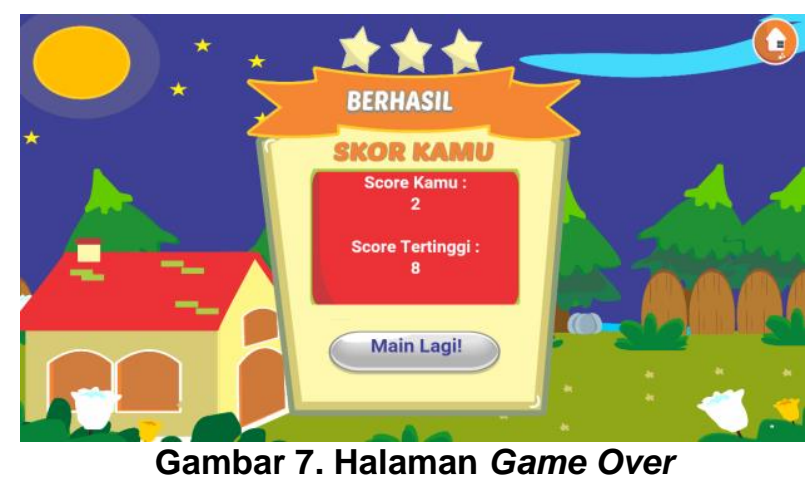

\subsubsection{Menu Ruang Belajar}

Dalam menu ruang belajar terdapat materi tentang pengenalan hewan dan tumbuhan disekitar kita serta materi siklus hidup hewan dan tumbuhan, user juga diberikan pilihan ingin mempelajari materi hewan dahulu atau tumbuhan dahulu. Materi keduanya ditampilkan dalam bentuk gambar dan penjelasan yang dapat digeser kekiri dan kekanan. Adapun tampilan dari menu ruang belajar ditunjukkan pada Gambar 8 .

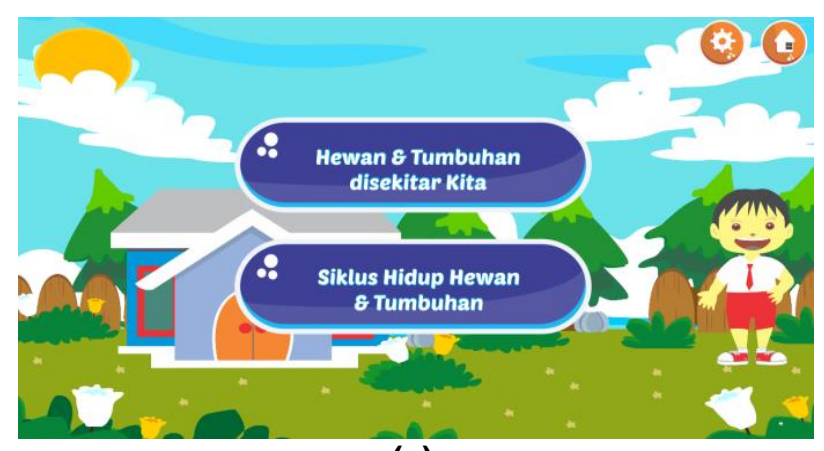

(a)

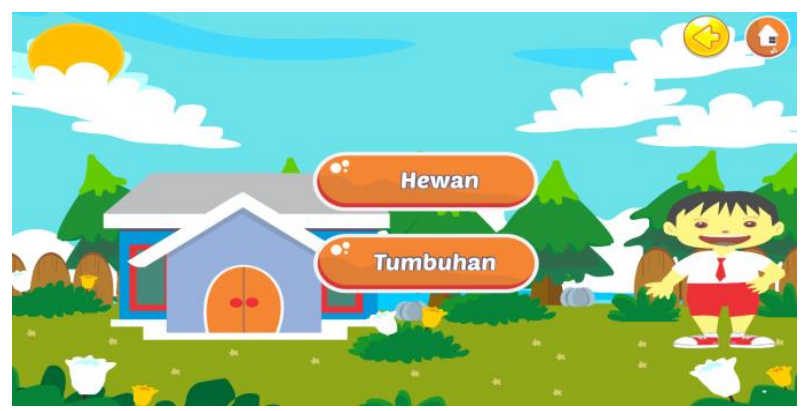

(b)

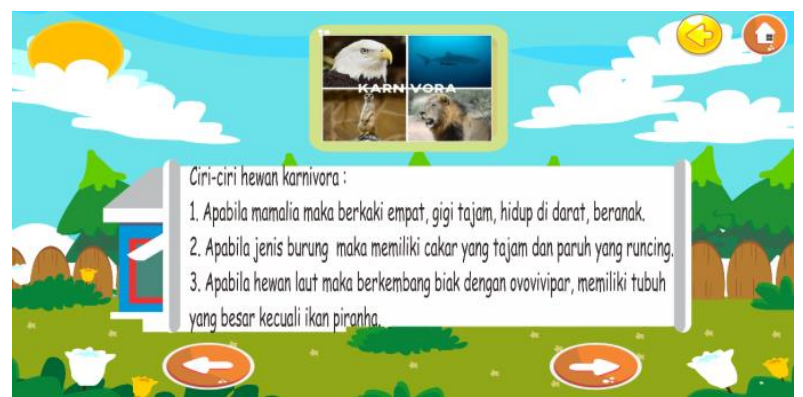

(c)

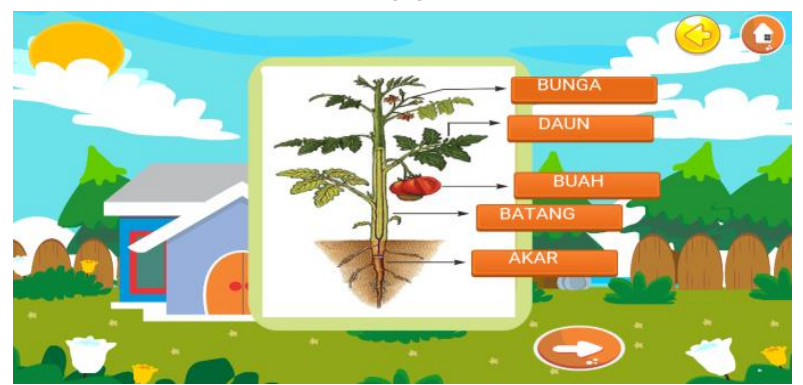

(d)

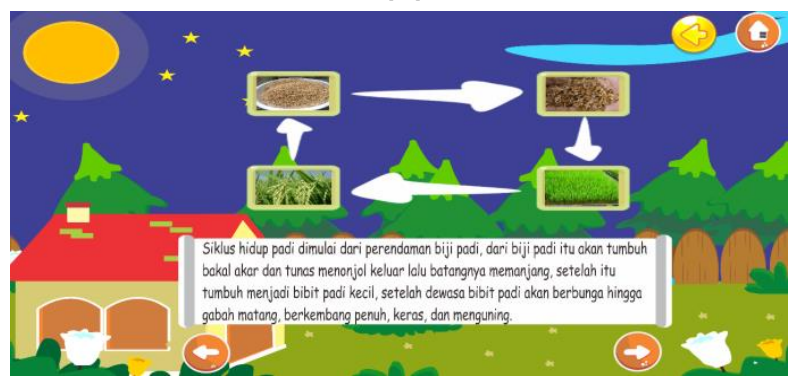

(e)

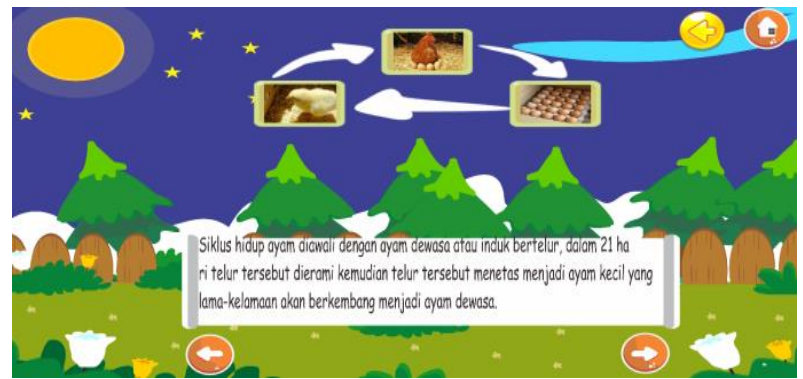

(f)

Gambar 8. Halaman Sub Menu Ruang Belajar

(a), Halaman Pilihan Materi Hewan Atau Tumbuhan (b), Halaman Materi Pengenalan Hewan (c), Halaman Materi Pengenalan Tumbuhan (d), Halaman Materi Siklus Hidup Tumbuhan (e), Halaman Materi Siklus Hidup Hewan (f) 


\subsection{Pengujian Blackbox}

Dalam tahap ini dilakukan pengujian Black box yang bertujuan untuk mengetahui apakah aplikasi ini dapat berjalan dan berfungsi sesuai yang telah diharapkan sebelumnya. Hasil dari pengujian Blackbox aplikasi ini ditunjukkan pada Tabel 3.

Tabel 3. Hasil Pengujian Blackbox

\begin{tabular}{|c|c|c|c|c|}
\hline Bagian & $\begin{array}{c}\text { Nama } \\
\text { Penguj } \\
\text { ian }\end{array}$ & $\begin{array}{c}\text { Bentuk } \\
\text { Pengujian }\end{array}$ & $\begin{array}{c}\text { Hasil } \\
\text { Yang } \\
\text { Dihara } \\
\text { p }\end{array}$ & Hasil \\
\hline \multirow{4}{*}{$\begin{array}{l}\text { Menu } \\
\text { Utama }\end{array}$} & $\begin{array}{l}\text { Mulai } \\
\text { Kuis }\end{array}$ & $\begin{array}{l}\text { Klik“ } \\
\text { Mulai" }\end{array}$ & $\begin{array}{l}\text { Muncul } \\
\text { Halama } \\
\text { n Kuis }\end{array}$ & Valid \\
\hline & $\begin{array}{l}\text { Mulai } \\
\text { Belajar }\end{array}$ & $\begin{array}{l}\text { Klik } \\
\text { "Ruang } \\
\text { Belajar" }\end{array}$ & $\begin{array}{l}\text { Muncul } \\
\text { Pilihan } \\
\text { Materi }\end{array}$ & Valid \\
\hline & $\begin{array}{l}\text { Menu } \\
\text { Tentan } \\
\mathrm{g}\end{array}$ & $\begin{array}{l}\text { Klik } \\
\text { "Tentang" }\end{array}$ & $\begin{array}{l}\text { Muncul } \\
\text { Halama } \\
\mathrm{n} \\
\text { Tentan } \\
\mathrm{g}\end{array}$ & Valid \\
\hline & $\begin{array}{l}\text { Menu } \\
\text { Pengat } \\
\text { uran }\end{array}$ & $\begin{array}{l}\text { Klik } \\
\text { "Pengatura } \\
\text { n" }\end{array}$ & $\begin{array}{l}\text { Muncul } \\
\text { Halama } \\
\mathrm{n} \\
\text { Pengat } \\
\text { uran }\end{array}$ & Valid \\
\hline \multirow{3}{*}{$\begin{array}{l}\text { Halaman } \\
\text { Kuis }\end{array}$} & $\begin{array}{l}\text { Penguji } \\
\text { an Kuis }\end{array}$ & Klik "Mulai" & $\begin{array}{l}\text { Menam } \\
\text { pilkan } \\
35 \text { Soal } \\
\text { Acak }\end{array}$ & Valid \\
\hline & $\begin{array}{l}\text { Penghit } \\
\text { ungan } \\
\text { Score }\end{array}$ & $\begin{array}{l}\text { Menjawab } \\
\text { Kuis }\end{array}$ & $\begin{array}{l}\text { Muncul } \\
\text { Tampil } \\
\text { an } \\
\text { Score } \\
\text { Dan } \\
\text { Highsc } \\
\text { ore }\end{array}$ & Valid \\
\hline & $\begin{array}{l}\text { Penguji } \\
\text { an } \\
\text { Jawaba } \\
n\end{array}$ & $\begin{array}{l}\text { Mengklik } \\
\text { Jawaban }\end{array}$ & $\begin{array}{l}\text { Jika } \\
\text { Benar } \\
\text { Menam } \\
\text { bah } \\
\text { Score } \\
\text { Jika } \\
\text { Salah } \\
\text { Game } \\
\text { Over }\end{array}$ & Valid \\
\hline $\begin{array}{l}\text { Halaman } \\
\text { Game } \\
\text { Over }\end{array}$ & $\begin{array}{l}\text { Ul } \\
\text { Game } \\
\text { Over }\end{array}$ & $\begin{array}{l}\text { Menyelesai } \\
\text { kan Kuis }\end{array}$ & $\begin{array}{l}\text { Menam } \\
\text { pilkan } \\
\text { Score } \\
\text { Dan } \\
\text { High } \\
\text { Score }\end{array}$ & Valid \\
\hline
\end{tabular}

Tabel 4. Lanjutan Hasil Pengujian Blackbox

\begin{tabular}{|c|c|c|c|c|}
\hline \multirow{3}{*}{$\begin{array}{l}\text { Halaman } \\
\text { Game } \\
\text { Over }\end{array}$} & $\begin{array}{l}\text { Keluar } \\
\text { Kuis }\end{array}$ & $\begin{array}{l}\text { Klik } \\
\text { "Home" }\end{array}$ & $\begin{array}{l}\text { Muncul } \\
\text { Pop Up } \\
\text { Pertany } \\
\text { aan } \\
\text { Konfirm } \\
\text { asi }\end{array}$ & Valid \\
\hline & $\begin{array}{l}\text { Penguji } \\
\text { an Pop } \\
\text { Up }\end{array}$ & $\begin{array}{l}\text { Mengklik } \\
\text { Tombol } \\
\text { "YA" dan } \\
\text { "Tidak" }\end{array}$ & $\begin{array}{l}\text { Jika Ya } \\
\text { Keluar } \\
\text { Quis, } \\
\text { Jika } \\
\text { Tidak } \\
\text { Tetap } \\
\text { Pada } \\
\text { Halama } \\
\text { n } \\
\text { Game } \\
\text { Over } \\
\end{array}$ & Valid \\
\hline & $\begin{array}{l}\text { Mengul } \\
\text { ang } \\
\text { Kuis }\end{array}$ & $\begin{array}{l}\text { Mengklik } \\
\text { Tombol } \\
\text { Main Lagi }\end{array}$ & $\begin{array}{l}\text { Memul } \\
\text { ai } \\
\text { Ulang } \\
\text { Kuis } \\
\end{array}$ & Valid \\
\hline \multirow{4}{*}{$\begin{array}{l}\text { Halaman } \\
\text { Ruang } \\
\text { Belajar }\end{array}$} & $\begin{array}{l}\text { Penguji } \\
\text { an } \\
\text { Materi } \\
\text { Pengen } \\
\text { alan } \\
\text { Hewan }\end{array}$ & $\begin{array}{l}\text { Mengklik } \\
\text { Tombol } \\
\text { Hewan }\end{array}$ & $\begin{array}{l}\text { Menam } \\
\text { pilkan } \\
\text { Materi } \\
\text { Pengen } \\
\text { alan } \\
\text { Hewan }\end{array}$ & Valid \\
\hline & $\begin{array}{l}\text { Penguji } \\
\text { an } \\
\text { Materi } \\
\text { Siklus } \\
\text { Hidup } \\
\text { Hewan }\end{array}$ & $\begin{array}{l}\text { Mengklik } \\
\text { Tombol } \\
\text { Siklus } \\
\text { Hidup } \\
\text { Hewan }\end{array}$ & $\begin{array}{l}\text { Menam } \\
\text { pilkan } \\
\text { Materi } \\
\text { Siklus } \\
\text { Hidup } \\
\text { Hewan }\end{array}$ & Valid \\
\hline & $\begin{array}{l}\text { Penguji } \\
\text { an } \\
\text { Materi } \\
\text { Pengen } \\
\text { alan } \\
\text { Tumbu } \\
\text { han }\end{array}$ & $\begin{array}{l}\text { Mengklik } \\
\text { Tombol } \\
\text { Tumbuhan }\end{array}$ & $\begin{array}{l}\text { Menam } \\
\text { pilkan } \\
\text { Materi } \\
\text { Pengen } \\
\text { alan } \\
\text { Tumbu } \\
\text { han }\end{array}$ & Valid \\
\hline & $\begin{array}{l}\text { Penguji } \\
\text { an } \\
\text { Materi } \\
\text { Siklus } \\
\text { Hidup } \\
\text { Tumbu } \\
\text { han }\end{array}$ & $\begin{array}{l}\text { Mengklik } \\
\text { Tombol } \\
\text { Siklus } \\
\text { Hidup } \\
\text { Tumbuhan }\end{array}$ & $\begin{array}{l}\text { Menam } \\
\text { pilkan } \\
\text { Materi } \\
\text { Siklus } \\
\text { Hidup } \\
\text { Tumbu } \\
\text { han } \\
\end{array}$ & Valid \\
\hline \multirow{3}{*}{$\begin{array}{l}\text { Halaman } \\
\text { Pengatur } \\
\text { an }\end{array}$} & $\begin{array}{l}\text { Penguji } \\
\text { an } \\
\text { Unmute } \\
\text { Audio }\end{array}$ & $\begin{array}{l}\text { Klik } \\
\text { Tombol "Y" }\end{array}$ & $\begin{array}{l}\text { Audio } \\
\text { Unmute }\end{array}$ & Valid \\
\hline & $\begin{array}{l}\text { Penguji } \\
\text { an } \\
\text { Mute } \\
\text { Audio }\end{array}$ & $\begin{array}{l}\text { Klik } \\
\text { Tombol "N" }\end{array}$ & $\begin{array}{l}\text { Audio } \\
\text { Mute }\end{array}$ & Valid \\
\hline & $\begin{array}{l}\text { Pengat } \\
\text { uran } \\
\text { Volume }\end{array}$ & $\begin{array}{l}\text { Menggeser } \\
\text { Slider } \\
\text { Volume }\end{array}$ & $\begin{array}{l}\text { Volume } \\
\text { Beruba } \\
\text { h } \\
\text { Sesuai } \\
\text { Perges } \\
\text { eran } \\
\text { Slider }\end{array}$ & Valid \\
\hline $\begin{array}{l}\text { Keseluru } \\
\text { han } \\
\text { Aplikasi }\end{array}$ & $\begin{array}{l}\text { Fungsi } \\
\text { Tombol }\end{array}$ & $\begin{array}{l}\text { Klik Setiap } \\
\text { Tombol }\end{array}$ & $\begin{array}{l}\text { Tombol } \\
\text { Berjala } \\
\mathrm{n} \\
\text { Sesuai } \\
\text { Fungsi }\end{array}$ & Valid \\
\hline
\end{tabular}


Dari hasil pengujian black box diatas maka dapat ditarik kesimpulan bahwa setiap fitur yang ada pada aplikasi ini dapat berjalan dengan baik sesuai dengan fungsinya.

Selain pengujian black box aplikasi, pengujian juga dilakukan pada perangkat mobile android, dimana perangkat mobile android sendiri menjadi platform dimana aplikasi ini beroperasi. Hasil Pengujian perangkat dijelaskan pada Tabel 5.

Tabel 5. Hasil Pengujian Perangkat

\begin{tabular}{|c|c|c|}
\hline Merk & Spesifikasi & Hasil \\
\hline $\begin{array}{l}\text { Samsung } \\
\text { Galaxy J7 } \\
\text { Prime }\end{array}$ & $\begin{array}{c}\text { Layar 5,5inch, } \\
\text { Ram 3GB, } \\
\text { CPU Octacore, } \\
\text { OS } \\
\text { Marshmallow }\end{array}$ & $\begin{array}{l}\text { Dapat } \\
\text { Terbuka, } \\
\text { Berjalan } \\
\text { Lancar }\end{array}$ \\
\hline $\begin{array}{l}\text { Samsung } \\
\text { Galaxy J2 } \\
\text { Prime }\end{array}$ & $\begin{array}{c}\text { Layar 5,0inch, } \\
\text { RAM 1,5GB, } \\
\text { CPU } \\
\text { Quadcore, OS } \\
\text { Marshmallow }\end{array}$ & $\begin{array}{c}\text { Dapat } \\
\text { Terbuka, } \\
\text { Sedikit Lagi } \\
\text { Pada } \\
\text { Halaman } \\
\text { Ruang } \\
\text { Belajar }\end{array}$ \\
\hline $\begin{array}{c}\text { Lenovo } \\
\text { A6010 Plus }\end{array}$ & $\begin{array}{c}\text { Layar 5,0inch, } \\
\text { RAM 2GB, } \\
\text { CPU } \\
\text { Quadcore, OS } \\
\text { Lolipop }\end{array}$ & $\begin{array}{l}\text { Dapat } \\
\text { Terbuka, } \\
\text { Berjalan } \\
\text { Lancar }\end{array}$ \\
\hline $\begin{array}{c}\text { Samsung } \\
\text { Galaxy Grand } \\
\text { Prime }\end{array}$ & $\begin{array}{c}\text { Layar 5,0inch, } \\
\text { RAM 1GB, } \\
\text { CPU } \\
\text { Quadcore, } \\
\text { Kitkat }\end{array}$ & $\begin{array}{c}\text { Dapat } \\
\text { Terbuka, } \\
\text { Force Close } \\
\text { Pada } \\
\text { Halaman } \\
\text { Ruang } \\
\text { Belajar } \\
\end{array}$ \\
\hline
\end{tabular}

Dari tabel pengujian diatas dapat disimpulkan bahwa aplikasi ini dapat berjalan dengan lancar pada platform android, tetapi pada smartphone dengan spesifikasi yang rendah terkadang terjadi force close dan lag saat membuka halaman tertentu, namun secara keseluruhan aplikasi ini sudah dapat berjalan dengan baik pada perangkat smartphone android.

\subsection{Pengujian Kepada Calon Pengguna}

Pengujian kepada calon pengguna ini diterapkan kepada Guru dan Siswa-Siswi kelas IV SD Negeri II Repaking Kabupaten Boyolali dengan menyebarkan kuisioner user acceptance test yang telah dijelaskan pada tahap sebelumnya. Koresponden pengujian ini adalah 6 Guru dan 24 Siswa-Siswi jadi total koresponden keseluruhan berjumlah 30 orang. Ukuran sampel yang layak untuk penelitian adalah antara 30 sampai dengan 500 [9].

Berdasarkan hasil rekapitulasi kuisioner maka skor ideal (kriterium) dihitung dengan menggunakan rumus persamaan 1 .

Skor Ideal $=\sum 5 \times$ Jumlah Responden ... (1)

Keterangan : 5 didapat dari nilai skala SS.

Jadi skor ideal (kriterium) dalam kuisioner ini adalah $\mathbf{5} \times \mathbf{3 0}=\mathbf{1 5 0}$.

Untuk perhitungan total nilai, setiap pertanyaan dihitung jumlah SS, S, N, TS, dan STS. Total nilai merupakan penjumlahan dari perkalian jumlah jawaban dikalikan dengan skala linkertnya. Sebagai contoh, pada P1 jumlah $S S=23, S=6, N=1, T S=0, S T S=0$.

Total nilai $=(23 \times 5)+(6 \times 4)+(1 \times 3)=142$.

Sedangkan untuk menghitung prosentase persetujuan dari hasil kuisioner diatas dapat dihitung dengan menggunakan rumus persamaan 2 berikut ini.

$$
\text { presentase }=\frac{\text { nilai }}{\text { skor ideal }} \times 100 \% \ldots \ldots \text {... }
$$

Dari kedua rumus persamaan diatas dapat disimpulkan hasil dari kuisioner user acceptance test seperti pada Tabel 6 di bawah ini.

Tabel 6. Hasil Pengujian User Acceptance Test

\begin{tabular}{|c|c|c|c|c|c|c|c|c|}
\hline \multirow[t]{2}{*}{ No } & \multirow{2}{*}{$\begin{array}{l}\text { Perta- } \\
\text { nyaan }\end{array}$} & \multicolumn{5}{|c|}{ Jumlah Jawaban } & \multirow{2}{*}{$\begin{array}{l}\text { Total } \\
\text { Nilai }\end{array}$} & \multirow{2}{*}{$\begin{array}{c}\text { Presen } \\
\text { tase }\end{array}$} \\
\hline & & $\begin{array}{l}\mathbf{S} \\
\mathbf{S}\end{array}$ & $\mathbf{S}$ & $\mathbf{N}$ & $\begin{array}{l}T \\
S\end{array}$ & $\begin{array}{l}\mathbf{S} \\
\mathbf{T} \\
\mathbf{S}\end{array}$ & & \\
\hline 1. & P1 & 23 & 6 & 1 & 0 & 0 & 142 & $94,7 \%$ \\
\hline 2. & $\mathrm{P} 2$ & 20 & 9 & 1 & 0 & 0 & 139 & $92,7 \%$ \\
\hline 3. & P3 & 17 & 11 & 2 & 0 & 0 & 135 & $90 \%$ \\
\hline 4. & P4 & 18 & 12 & 0 & 0 & 0 & 138 & $92 \%$ \\
\hline 5. & P5 & 17 & 13 & 0 & 0 & 0 & 137 & $91,3 \%$ \\
\hline 6. & P6 & 22 & 8 & 0 & 0 & 0 & 142 & $94,7 \%$ \\
\hline 7. & P7 & 19 & 11 & 0 & 0 & 0 & 139 & $92,7 \%$ \\
\hline 8. & P8 & 23 & 6 & 1 & 0 & 0 & 142 & $94,7 \%$ \\
\hline 9. & P9 & 23 & 7 & 0 & 0 & 0 & 143 & $95,3 \%$ \\
\hline 10. & $\mathrm{P} 10$ & 24 & 6 & 0 & 0 & 0 & 144 & $96 \%$ \\
\hline \multicolumn{8}{|c|}{ Nilai Presentase Rata-Rata } & $93,4 \%$ \\
\hline
\end{tabular}

Hasil dari pengujian user acceptance diatas dapat dilihat pada diagram batang pada Gambar 9. 


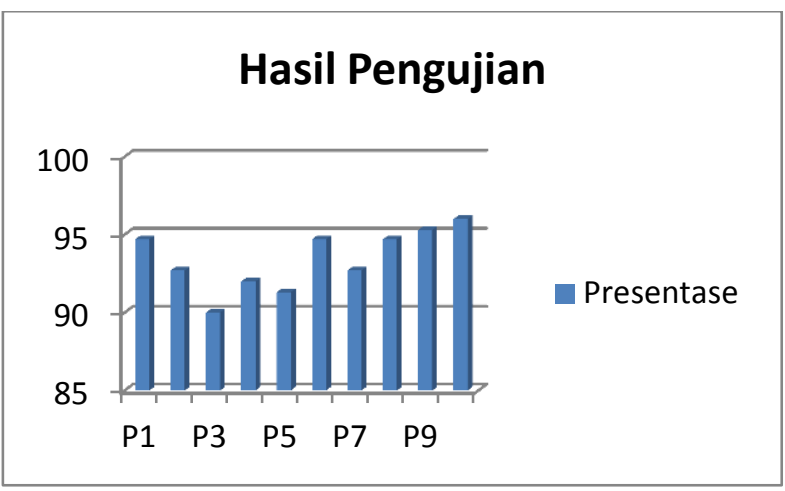

Gambar 9. Diagram Hasil Penghitungan Kuisioner

\section{PENUTUP}

\subsection{Kesimpulan}

Setelah tahap analis, pembuatan aplikasi, dan pengujian terhadap aplikasi ini telah selesai dilakukan, maka penulis dapat menyimpulkan sebagai berikut.

1. Nilai rata-rata presentase tingkat penerimaan pengguna adalah $93,4 \%$, hal itu menunjukkan bahwa aplikasi ini menarik perhatian bagi siswa-siswi sekolah dasar kelas IV, serta dapat membantu meningkatkan minat belajar siswa-siswi dalam mempelajari lingkungan disekitarnya khususnya tentang hewan dan tumbuhan di sekitar mereka. Aplikasi ini berjalan dengan lancar, bahasanya mudah dimengerti, materi yang terdapat dalam aplikasi ini mudah dipahami, serta tombol-tombol yang ada dapat berjalan sesusai dengan fungsinya.

2. Aplikasi ini dapat berjalan pada smartphone yang memakai sistem operasi android dengan lancar, aplikasi menampilkan tampilan fullscreen pada smartphone android.

\subsection{Saran}

1. Menambahkan materi pembelajaran IImu Pengetahuan Alam yang lebih lengkap agar menambah fungsi kegunaan aplikasi ini.

2. Menyempurnakan tampilan agar lebih interaktif.

\section{DAFTAR PUSTAKA}

[1] M. Ngafifi, "Advances in Technology and Patterns of Human Life in Socio-Cultural Perspective," Kemajuan Teknol. dan Pola Hidup Mns., vol. 2, no. 1, pp. 33-47, 2014.

[2] R. Delima, N. K. Arianti, and B. Pramudyawardani, "Identifikasi Kebutuhan Pengguna Untuk Aplikasi
Permainan Edukasi Bagi Anak Usia 4 sampai 6 Tahun," Tek. Inform. dan Sist. Inf., vol. 1, no. April, pp. 1-8, 2015.

[3] $\mathrm{H}$. Supriyono et al., "Rancang Bangun Media Pembelajaran Bahasa Dan Huruf Jawa Berbasis Adobe Flash CS6", The 2 nd University Research Coloquium 2015 ISSN 2407-9189," pp. 1-9, 2015.

[4] A. R. Pratiwi, "Pengaruh Gaya Mengajar Guru Terhadap Minat Kebudayaan Islam Di Mts Negeri Karanganyar", Skripsi, 2017.

[5] F. Arifin, T. Abidin, and M. Humam, "Game Edukasi Pengenalan Cara Hidup Hewan Dan Tumbuhan Untuk Anak Usia Sekolah Dasar Kelas 4," pp. 54-60, 2003.

[6] D. W. Putra, A. P. Nugroho, and E. W. Puspitarini, "Game Edukasi Sebagai Media Pembelajaran Pendidikan Anak Usia Dini," J. Inform. Merdeka Pasuruan, vol. 1, no. 1, pp. 1-8, 2016.

[7] H. Sulistyanto, "Urgensi Pengujian pada Kemajemukan Perangkat Lunak dalam Multi Perspektif," Komuniti, vol. 6, no. 1, pp. 65-74, 2017.

[8] A. B. Mutiara, "Testing implementasi website rekam medis elektronik opeltgunasys dengan metode acceptance testing," vol. 8, no. Kommit 2014, pp. 1-7, 2015.

[9] P. Sugiyono, " Metod. Penelit. Kuantitatif, Kualitatif, dan R\&D", Bandung CV Alf., 2010. 